\title{
Cystic eChinococcosis in Greece. Past and present ${ }^{1}$
}

\author{
SOTIRAKI S.* \& CHALIGIANNIS I.*
}

\section{Summary:}

Cystic echinococcosis is a zoonotic disease with a wide geographical distribution, Greece included, and is considered to be a serious problem for the public health and the livestock economy. Although the disease was widespread in Greece since ancient times, cystic echinococcosis was identified as a serious problem around 1970, and since then national surveillance programmes are running, based on meat inspection and stray dogs management. Ever since, there are official records of the parasite's prevalence in humans and livestock which show a continuous decline. More precisely, human hydatidosis, according to the official records, declines from an annual incidence of 14.8 per 100,000 inhabitants during 1967-1971 to 0.3 in 2008. Late surveys reveal that in Greece the prevalence of echinococcosis was 23-39.2\% for sheep, 7.6-14.7\% for goats, $0 \%$ in cattle and $0.6 \%$ in pigs, while further molecular analyses in Southern Greece showed the existence of the genotypes G1 and G3 in sheep and $\mathrm{G} 7$ in goats in that area. All data presented demonstrate that the parasite is still present in Greece. Surveillance is nowadays being performed under EU regulations but it is highly important to improve and adopt corrective and preventive measures to avoid animal and human infection.

KEY WORDS: cystic echinococcosis, Echinococcus granulosus, surveillance, Greece.

$\mathrm{E}$ chinococcosis is a parasitic disease that occurs as a result of infection by taeniid cestodes belonging to the genus Echinococcus. Globally, six species have been recognized, of which four are of public health concern (only the first two occur in Europe), E. granulosus (causing cystic echinococcosis), E. multilocularis (causing alveolar echinococcosis), E. vogeli and E. oligarthrus (causing polycystic echinococcosis) (Moro \& Schantz, 2009). The other two, which have been recently identified and their zoonotic potential is unknown, are E. shiquicus, found in small mammals from the Tibetan

\footnotetext{
* VRI-NAGREF, 57001 Thermi, Thessaloniki, Greece. Correspondence: S. Sotiraki

Tel.: +302310365373 - Fax: +302130365371

E-mail: sotiraki@vri.gr, smaro_sotiraki@yahoo.gr

${ }^{1}$ This article is based on an oral presentation given at the international conference "Parasitic zoonoses in present day Europe", Belgrade, 18-20 November 2009 .
}

Résumé : L'hydatidose en Grèce. Passé et présent

L'hydatidose à Echinococcosus granulosus est une zoonose qui a une large distribution géographique, la Grèce incluse, et qui est un important problème pour la santé publique et l'économie de l'élevage. Bien que la maladie soit connue en Grèce depuis longtemps, elle a été considérée comme étant un problème sérieux dans les années 1970 et des programmes de surveillance nationaux fonctionnent depuis, basés sur l'inspection de la viande et la gestion des chiens errants. Depuis, les données officielles montrent une baisse continue de la fréquence de la maladie chez I'homme et le bétail. Plus précisément, l'incidence annuelle des cas de kystes hydatiques humains est passée de 14,8 pour 100000 habitants durant les années 1967-1971 à 0,3 en 2008. Les dernières enquêtes révèlent que la fréquence de l'hydatidose animale en Grèce est de 23-39,2 \% chez les ovins, de 7, 6-14,7\% chez les caprins, de $0 \%$ chez les bovins et de 0,6\% chez les porcins. Des analyses menées en Grèce du sud ont montré l'existence des génotypes $G 1$ et $G 3$ chez les ovins et $G 7$ chez les caprins dans ce secteur. Toutes les données démontrent que le parasite est toujours présent en Grèce. La surveillance est de nos jours en conformité avec la réglementation de l'Union européenne, mais il est très important d'améliorer les mesures de prévention de la maladie tant chez l'animal que chez l'homme.

MOTS CLÉS : hydatidose, kyste hydatique, Echinococcus granulosus, surveillance, Grèce.

plateau (Xiao et al., 2006) and E. felidis, found in African lions (Hüttner et al., 2008).

In Europe, Echinococcus is present in livestock and wildlife being pathogenic to humans and several studies have shown that it's an increasing public health concern regarded as emerging or re-emerging zoonosis. Pathology, epidemiology and geographic distribution vary significantly among the different Echinococcus species. As a general rule, echinococcosis in man caused by species mainly transmitted by wild animals is rare, due to limited contact between humans and wildlife. However, in Europe E. multilocularis is considered an emerging parasite (the annual incidence in endemic areas has increased from a mean of 0.10 per 100,000 inhabitants during 1993-2000 to a mean of 0.26 per 100,000 inhabitants during 2001-2005), principally due to the movement, relocation and increase in the fox population, mainly after the successful establishment of anti-rabies vaccination programs (Schweiger et al., 2007). 
South-western and Eastern Europe are considered endemic regions for the E. granulosus complex. E. granulosus is the most important species in relation to food producing animals (i.e. cattle, sheep, goat, pig, deer, boar, etc). E. granulosus consists of various genotypes/ (sub)species recently redefined (Thompson, 2008; Nakao et al., 2007). At least seven of nine E. granulosus genotypes are infective to humans, four of which exist in Europe. Globally, most human cases of cystic echinococcosis (CE) are caused by the sheep strain G1 of E. granulosus which predominantly has a dog-sheep cycle (Eckert \& Deplazes, 2004).

The aim of this paper is to review the past and current situation as regards CE in Greece and to describe the national monitoring programmes and the results of their application.

\section{BACKGROUND}

I

n Greece, E. granulosus has been acknowledged as a common species since ancient times, described by Hippocrates (as "cysts full of water" in a liver of a man), and Aristotle (Sotiraki et al., 2003). In modern Greece, the first recognised human infection was reported in 1839. The disease was obviously widespread but unfortunately before 1970 s, it was practically not possible to collect accurate national epidemiological data. According to the National Statistical Service of Greece and the Greek Ministry of Health the incidence of human cystic echinococcosis for the years 1967-1981 was estimated at 12.9 per 100,000 inhabitants. As for the livestock species, the official prevalence from 1973 to 1977 was $53 \%$ for cattle raised outdoors, $17.9 \%$ for cattle raised indoors, $61 \%$ for sheep, $7.2 \%$ for goats and $1.9 \%$ for pigs (Vassalos et al., 1984, Tsaglas, 1985). At that time, as a result of the high prevalence of infection in animals and man, the economic losses caused by this disease in Greece had been calculated at approximately 3,671,357,000 Greek drachmas (10,774,342 Euros) (Tsaglas, 1985). In the following text we will review the programmes that were and are implemented ever since and analyse their efficiency based on published records.

\section{ANTI-ECHINOCOCCOSIS CONTROL POLICY}

\footnotetext{
A $s$ described above, CE was identified as a serious problem around 1970, and in 1978 (law nr. $829 / 78$ ) a national control program was established which was elaborated in 1984 (degree-law 400/84). The main principles of this program were identification and registration of all dogs, elimination of stray dogs, routine praziquantel treatment of shepherd dogs
}

every 5-6 weeks, selective treatment of all other infected dog (diagnosed by examination of faecal specimens obtained by arecoline purges), abattoir control and meat inspection (Sotiraki et al., 2003).

Since Greece joined the EU, surveillance is performed during official meat inspection as part of EC Regulation No 854/2004 (relevant Greek PO 79/07) of the European Parliament and of the Council of 29 April 2004, which laid down specific rules for the organisation of official control of products of animal origin intended for human consumption. Monitoring of echinococcosis / hydatidosis is covered by the Directive 2003/99/EC (EC, 2003), which forms the basis for the data on zoonoses collected throughout the member states and reported to the EU Commission on an annual basis. These data are collected and examined by the European Food Safety Authority (EFSA), the European Centre for Disease Control (ECDC) and by the Zoonoses Collaboration Centre (ZCC). Echinococcus is included in list A of Annex I, Directive 2003/99/EC, which determines which agents have to be monitored on a mandatory basis. According to the above, the measures in force designate that all carcasses intended for human consumption are inspected for evidence of hydatid cysts and cyst identification leads to condemnation of the part of the carcass.

In addition, and to support meat inspection, there is a national legal basis in force for stray dogs (Law 3170/2003), based on the animal welfare principles and the European Convention for the Protection of Pet Animals, and in respect to animal and public health. The current framework succeeded a previous one (Law 829/78), which was actually the legal basis for the control program for echinococcosis, rabies and leishmaniosis implemented from 1983 to 1994. This legislation basically encompasses the registration of all dogs (owned and stray), and the collection and clinical examination of stray dogs, followed by spaying of bitches, adoption/return to the existing owners or release, under certain conditions, of the animals into the environment.

\section{HUMAN HYDATIDOSIS}

According to the Greek Ministry of Health, the incidence of human cystic echinococcosis for the years 1967-1971, 1972-1976 and 1977-1981 was, respectively, 14.8, 12.9, and 10.9 per 100,000 inhabitants. A retrospective study to estimate the incidence of hydatidosis among Greeks between 1969 and 1975 (Karpathios et al., 1985) showed that during this period a total of 4202 adult patients were diagnosed with hydatidosis, indicating an incidence of 9.77 per 100,000 inhabitants. Of these, 3397 $(80.8 \%)$ patients underwent surgery (485 per year or 7.9 surgical cases per 100,000 inhabitants). For the 
period 1981-83, Papadopoulos (1985) reported an incidence of 12.7 per 100,000 inhabitants (range 11.6-13.35).

Official data from the Ministry of Public Health indicate 54 cases reported in 1998, 51 in 1999, 29 in 2000, 41 in 2001, 23 in 2002, 16 in 2003, 26 in 2004, 11 in 2005, 5 in 2006, 49 in 2007, while in 2008, 8 cases were reported until May. According to the EFSA Journal (2010), and on a case report basis, a total of 25 cases were reported in 2004, while in 2005, 2006, 2007 there were 10,5 , and 10 confirmed cases, respectively, and in 2008 there were 31 total cases, of which 28 were confirmed (0.3/100,000 inhabitants).

As regards recent published records, they are not available on a national basis, but there is a number of scientific reports from single clinics / hospitals from throughout the country. More precisely, records from Athens include 85 surgically treated patients between 1986 and 1996 in Evangelismos General Hospital (Athanasiadi et al., 1998) and 194 patients between 1996 and 2006 in Hippocrateion Hospital. In the latter, there were also three gluteus muscle cysts reported during the last 10 years and one liver cyst in 2007 (Manouras et al., 2007; Manouras et al., 2009). In Asclepeion Voulas Hospital, during a 20 years period, 35 patients (34\% male, $66 \%$ female were treated surgically for liver cysts (Avgerinos et al., 2006), while in the Red Cross Hospital one case each of liver cysts (Anthi et al., 2004) and of hydatid disease of the tarsal bones (Papanikolaou et al., 2005) were reported. Finally, the University of Athens School of Medicine reported 50 cases of liver hydatid cysts between 1993 and 1997 (Voros et al., 1999), and one cyst of the subcutaneous tissue (Safiolas et al., 2007).

In Thessaloniki, in AHEPA Hospital, a total of 615 patients were operated for hydatid disease between 1967 and 1998, 220 of them having cysts in more than one organ (Prousalidis et al., 2004) while 75 cases of calcified liver hydatidosis were reported between 1964 and 1996, (Prousalidis et al., 1999). Furthermore, in Hippocrateion Hospital, Papathanasiou et al. (2006) reported a hydatid cyst in the seminal vesicle.

In Medical School of Patras, 67 patients with hepatic hydatidosis were operated between 1985 and 1990 (Vagianos et al., 1995) and in the State Hospital of Corfu Island seven patients (three female, four male) were operated for hepatic cysts during the last 14 years (http://www.ixek.gr; 2009). Finally, cases were also reported in Larissa (Tepetes et al., 2007), Crete Island (Petrakis et al., 2009), and Lesvos Island (Kouskos et al., 2007).

In addition, there are a few reports of E. multilocularis infection in humans (Tzamouranis, 1969; Theodoropoulos et al., 1978), but there are doubts as to the reliability of this diagnosis.

\section{ECHINOCOCCOSIS IN LIVESTOCK SPECIES AND IN DEFINITIVE HOSTS}

oncerning the intermediate hosts, the prevalence of hydatidosis in different animal species has varied significantly over the last forty years. From 1975 to 1977 , according to official meat inspection data, the prevalence of infected animals was $53 \%$ for cattle raised outdoors, $17.9 \%$ for cattle raised indoors, $61 \%$ for sheep, $7.2 \%$ for goats and $1.9 \%$ for pigs (Vassalos et al., 1984; Tsaglas, 1985). At the initiation of the National control program in 1984, official prevalence estimates were $82 \%$ in cattle, $80 \%$ in sheep, $24 \%$ in goats and $5 \%$ in pigs (Sotiraki et al., 2003).

According to a study by Himonas et al. (1987), cyst fertility in 601 cysts from 103 sheep, 194 cysts from 77 goats, 528 cysts from 107 cattle and 102 cysts from 60 pigs, was respectively $64.2 \%(73.8 \%$ of the infected animals carrying fertile cysts), $54.6 \%$ (57.1\% of the infected animals carrying fertile cysts), $16.1 \%$ (30.8\% of the infected animals carrying fertile cysts), $6.9 \%$ ( $8.3 \%$ of the infected animals carrying fertile cysts). The fertility rate was higher in cysts in lungs that in those in liver in sheep and goats and vice versa in cattle and pigs. In a later study conducted in the same area, involving a total of 200 sheep, the percentage of infected animals was $100 \%$ with a mean of 1.1 (29.8\% of total cysts) fertile cysts per animal. Moreover, in the same survey in 106 cattle, 203 pigs and 52 goats examined, the percentage of infected animals was $56.6 \%, 9.3 \%$ and $15.4 \%$, and the mean rate of fertile cysts per animal of 0.1 (6.6 \% of total cysts), 0.02 ( $9.5 \%$ of total cysts), and 0.1 (12.5\% of total cysts) respectively. The fertility rate was higher among the cysts in lungs that in those in liver in sheep, pigs and goats and vice versa in cattle (Himonas et al., 1994).

The official data of the infected animals from 1999 to 2008 are shown in Table I (a, b).

In a survey conducted from 1998 to 2002 in Northern Greece (Sotiraki et al., 2003), the prevalence of infection was $31.3 \%$ in sheep $(0.7 \%$ in animals $<1$ year old, $2.2 \%$ in those $1-2$ years old, $70.7 \%$ in animals $>2$ years old), $10.3 \%$ in goats ( $0 \%$ in animals $<1$ year old, $13.6 \%$ in animals $>2$ years old), $0.6 \%$ in pigs, and $0 \%$ in cattle. Of the cysts examined, above $8 \%$ of the sheep ones were fertile, none of the infected goats, and all cysts recovered from pigs were calcified. During the year 2005, in a survey carried out in Peloponnese, Southern Greece, the prevalence recorded was $30.4 \%$ for sheep and $14.7 \%$ for goats. A total of 1,045 and 152 hydatid cysts were found, respectively, in infected sheep and goats, with a respective abundance of 5.0 and 0.8 . Fertile cysts were found in $16.2 \%$ of sheep and $7.4 \%$ of goats, with fertility rates of $39.8 \%$ for sheep and $22.4 \%$ for goats. Further analyses revealed G1 
(common sheep strain) and G3 (buffalo) genotypes in sheep, and G7 (pig) in goats (Varcasia et al., 2007). In another survey carried out between 2002 and 2006 in Thessaly, Central Greece, the prevalence in sheep was $39.3 \%$ in 700 hoggets and 1,500 adult sheep. The proportion of fertile hydatid cysts was significantly higher in hoggets (95.65\% for liver and $90 \%$ for lungs) than in adult sheep (78.79\% for liver and $73.42 \%$ for lungs) (Christodoulopoulos et al., 2008). More recently, in an ongoing survey in various slaughterhouses in Northern Greece, among 949 animals (567 sheep and 382 goats) 160 were found to be infected by E. granulosus $(16.9 \%)$. The prevalence among slaughtered sheep and goats was $23 \%$ and $7.6 \%$ respectively (Chaligiannis et al., unpublished data). Infection in other animals has not been reported except for a recent survey in horses, in which a seroprevalence of $0.1 \%$ was recorded (Kouam et al., 2010).

Finally, information concerning dogs is scarce. The infection prevalence in approximately 550,000 dogs at the initiation of the first programme was $50.4 \%$ for shepherd dogs, $26.9 \%$ for watch dogs, $19.2 \%$ for hunting dogs, $9.3 \%$ for stray dogs and $0.1 \%$ for companion dogs (Himonas, 1968; Vasalos, 1978; Tsaglas, 1985). Later on, from 1985 to 1987 , a mass diagnostic examination by the arecoline dosing technique performed by the National Veterinary Services showed E. granulosus infection in purged stools of $3.3 \%$ of 110,093 dogs (Papadopoulos, 1989). The same species was also reported in wolves (Papadopoulos, 1989). According to the EFSA Journal (2007), infection among owned dogs has almost disappeared due to the systematic preventive treatment of animals with antiparasitic drugs. The infection of stray dogs is decreasing overtime. E. multilocularis has not been documented in Greece.

a - from 1999 to 2001 (source: Hellenic Ministry of Rural Development and Food)

\begin{tabular}{lccccc}
\hline \multirow{2}{*}{$\begin{array}{c}\text { Year } \\
\text { of } \\
\text { examination }\end{array}$} & \multicolumn{5}{c}{ \% infected during meat inspection } \\
\cline { 2 - 6 } & $\mathbf{1 9 9 7}$ & $\mathbf{1 9 9 8}$ & $\mathbf{1 9 9 9}$ & $\mathbf{2 0 0 0}$ & $\mathbf{2 0 0 1}$ \\
\hline Cattle & 0.95 & 1.7 & 2.26 & 3.39 & 1.86 \\
Sheep & 5.3 & 2.6 & 3.23 & 2.78 & 3.21 \\
Goats & 1.5 & 0.39 & 0.69 & 0.8 & 0.8 \\
\hline
\end{tabular}

b - from 2004 to 2008 (source: EFSA Journal)

\begin{tabular}{lccccc}
\multirow{4}{*}{$\begin{array}{c}\text { Year } \\
\text { of } \\
\text { examination }\end{array}$} & \multicolumn{4}{c}{ \% infected during meat inspection } \\
\cline { 2 - 6 } & $\mathbf{2 0 0 4}$ & $\mathbf{2 0 0 5}$ & $\mathbf{2 0 0 6}$ & $\mathbf{2 0 0 7}$ & $\mathbf{2 0 0 8}$ \\
\hline Cattle & 1.18 & 0.93 & 0.97 & 1.44 & 1.09 \\
Sheep & 1.89 & 1.64 & 2.03 & 3.91 & 1.5 \\
Goats & 0.31 & 0.35 & 0.41 & 1.94 & 0.52 \\
Pigs & 0 & 0.008 & 0.02 & 0.004 & 0.001 \\
\hline
\end{tabular}

Table I. - Prevalence of Echinococcus in slaughtered animals.

\section{CONCLUSIVE REMARKS}

The data reviewed above are obviously controversial especially when official records are compared with research data. National surveillance programmes are usually based on meat inspection records but the sensitivity of meat inspection is rather low (Aalten et al., 2008). Therefore low infection levels will not be detected especially when meat inspection is carried out fast and/or is not adequately supported by a sufficient number of official veterinarians. In addition, cases that lead to total condemnation are being notified to central authorities whereas those with only partial viscera condemned due to the presence of hydatid cysts remain unregistered.

Attempts to synthesize the diverse data sources may misjudge the real situation. The numbers of human cases, even when only based on national reports, cannot be disregarded. The numbers of annual cases may seem small but yet they stand among the top in Europe, making $\mathrm{CE}$ a very important public health threat in Greece. It is also important to consider that most clinical figures given refer to surgical indexes (patients that had an operation). This leads to only a few cases officially being reported in comparison to the total numbers diagnosed, which can guide to underestimating the real situation. On the other hand, published data are often drawn from partial, occasional or targeted surveys concerning human and animal case studies (Ecca et al., 2001). Such case studies were often limited to specific specialized branches of surgery, to specific or unusual localizations of the parasite and to retrospective studies in single hospitals or clinics. Though these data are only estimates and of little epidemiological significance, they are indicative of the presence of the parasite in a specific area and often provide significant clinical information.

Overall, all data presented confirm that the parasite is still circulating among livestock and humans in Greece. Due to diagnostic difficulties in the definitive host and the asymptomatic character of the disease in the intermediate hosts in the case of E. granulosus, the monitoring of the disease must be performed at the slaughterhouse level. Therefore, it is important to improve the level of identification and notification of hydatid cysts findings by improved slaughterhouse registration and meat inspection practices. Furthermore, there is an urgent need to improve and adopt corrective and preventive measures to avoid animal and human infection, such as anthelmintic treatment of owned dogs, strict stray dog policy, strong veterinary control to avoid home slaughtering of sheep, goats and other livestock, and supervision of slaughtering facilities, i.e. destruction of infected offal. Moreover, additional measures such as the education of farmers and general public are a key action in the control of this infection in animals and humans. 


\section{REFERENCES}

Aalten M., ZÜchner L., Bruinier E., Holzhauer M., Wouda W., Borgsteede F., Sprong H. \& van der Giessen J. Reintroduction of E. granulosus by import of cows in the Netherlands. Tijdschr Diergeneeskd, 2008, 133 (21), 898-902.

Anthi A., Katsenos C., Georgopoulou S. \& Mandragos K. Massive rupture of a hepatic hydatid cyst associated with mechanical ventilation. Anesth. Analg., 2004, 98 (3), 796-797.

Athanasiadi K., Kalavrouziotis G., Loutsidis A., Dellenis I. \& EXARCHOS N. Surgical treatment of echinococcosis by a transthoracic approach: a review of 85 cases. Eur. J. Cardiothorac. Surg., 1998, 14 (2), 134-140.

Avgerinos E.D., Pavlakis E., Stathoulopoulos A., Manoukas E., SkARPAS G. \& TSATSOUlis P. Clinical presentations and surgical management of liver hydatidosis: our 20 year experience. HPB Surgery, 2006, 8 (3), 189-93.

Christodoulopoulos G., Theodoropoulos G. \& Petrakos G. Epidemiological survey of cestode-larva disease in Greek sheep flocks. Veterinary Parasitology, 2008, 153, 368-373.

Ecca A.R., Conchedda M., Gabriele F., Bortoletti G. \& Palmas C. Cystic echinococcosis in the Mediterranean basin, in: Cestode zoonoses: echinococcosis and cysticercosis. Craig P. \& Pawlowski Z. (Eds), IOS Press NATO Sciences Series, 2001, 41-55.

ECKert J. \& Deplazes P. Biological, epidemiological and clinical aspects of echinococcosis, a zoonosis of increasing concern. Clin. Microbiol. Rev., 2004, 17, 107-135.

EC (European Community), 2003. Directive 2003/99/EC of the European Parliament and of the Council of 17 November 2003 on the monitoring of zoonoses and zoonotic agents, amending Council Decision 90/424/EEC and repealing Council Directive 92/117/EEC, OJ L325, 12.12.2003, pp. 31-40.

EC (European Community), 2004. Regulation (EC) No 854/2004 of the European Parliament and of the Council of 29 April 2004 laying down specific rules for the organisation of official controls on products of animal origin intended for human consumption, OJ L 139, 30.4.2004, pp. 206-320.

EFSA, 2006. The Community Summary Report on trends and sources of zoonoses and zoonotic agents, antimicrobial resistance and food-borne outbreaks in the European Union in 2004. The EFSA Journal, 2005

EFSA, 2007. The Community Summary Report on trends and sources of zoonoses and zoonotic agents, antimicrobial resistance and food-borne outbreaks in the European Union in 2005. The EFSA Journal, 2006.

EFSA, 2008. The Community Summary Report on trends and sources of zoonoses and zoonotic agents, antimicrobial resistance and food-borne outbreaks in the European Union in 2006. The EFSA Journal, 2007.

EFSA, 2009. The Community Summary Report on trends and sources of zoonoses and zoonotic agents in the European Union in 2007. The EFSA Journal, 2009,

EFSA, 2010. The Community Summary Report on trends and sources of zoonoses and zoonotic agents and food-borne outbreaks in the European Union in 2008, The EFSA Journal, 2010, 1496.

Himonas C. Parasites of dog in Greece and their importance to public health. Dissertation. Yearbook of Veterinary School Vol. 9 AUTH, Greece, 1968.

Himonas C., Frydas S. \& Antoniadou-Sotiriadou K. The fertility of hydatid cysts in food animal in Greece. Helminth Zoonoses, 1987, 11-21.

Himonas C., Antoniadou-Sotiriadou K. \& Papadopoulos E. Hydatidosis of food animals in Greece: Prevalence of cysts containing viable protoscoleces. J. Helminthol., 1994, 68 (4), 311-313.

Hüttner M., Nakao M., Wassermann T., Siefert L., BoOmker J.D., Dinkel A., Sako Y., Mackenstedt U., Romig T. \& Ito A. Genetic characterization and phylogenetic position of Echinococcus felidis (Cestoda: Taeniidae) from the African lion. Int. J. Parasitol., 2008, 38 (7), 861-868.

Karpathios T., Fretzayas A., Nikolaidou P., Papadellis F., Vassalos M., Tselentis I., Thomaidis T. \& Matsaniotis N. Statistical aspects of hydatid disease in Greek adults. Am. J. Trop. Med. Hyg., 1985, 34, 124-128.

Kouam M.K., Diakou A., Kanzoura V., Papadopoulos E., Gajadhar A.A. \& Theodoropoulos G. A seroepidemiological study of exposure to Toxoplasma, Leishmania, Echinococcus and Trichinella in equids in Greece and analysis of risk factors. Vet. Parasitol., 2010, doi:10.1016/ j.vetpar.2010.02.004

Kouskos E., Chatziantoniou J., Chrissafis I., Anitsakis C. \& Zamtrakis S. Uncommon locations of hydatid cysts. Singapore Med.J., 2007, 48 (4), e119.

Manouras A., Genetzakis M., Antonakis P., Lagoudianakis E., Pattas M., Papadima A., Giannopoulos P. \& Menenakos E. Endoscopic management of a relapsing hepatic hydatid cyst with intrabiliary rupture: A case report and review of the literature. Can. J. Gastroenterol., 2007, 21 (4), 249-253.

Manouras A., Lagoudianakis E. E., Markogiannakis H., LarentZakis A., Kekis P., Filis K., Bramis C. \& Katergiannakis V. Primary hydatidosis of the gluteus muscles: report of three cases. Ir.J. Med. Sci., 2009, 178, 359-362.

Moro P. \& Schantz P.M. Echinococcosis: a review. Int. J. Inf. Diseases, 2009, 13, 125-133.

Nakao M., McManus D.P., Schantz P.M., Craig P.S. \& Ito A. A molecular phylogeny of the genus Echinococcus inferred from complete mitochondrial genomes. Parasitology, 2007, 134, 713-722.

PAPAdOPOUlOS H. Research on the contribution of wild carnivores in the epizootiology - epidemiology of echinococcosis-hydatidosis in Greece. Doctoral Thesis, Aristotle University Thessaloniki, Greece, 1989.

PApadopoulos G. Echinococcosis / hydatidosis in the world. Epizootiological and epidemiological analysis: problems in the Mediterranean area. Abstr. XIII Congreso International de Hidatologia, Madrid, 1985, 21-24.

Papanikolaou A., Antoniou N., PaVlakis D. \& Garas G. Hydatid disease of the tarsal bones. A case report. The Journal of Foot E Ankle Surgery, 2005, 44 (5), 396-400. 
Papathanasiou A., Voulgaris S., Salpiggidis G., Charalabous S., Fatles G. \& Rombis V. Hydatid cyst of the seminal vesicle. Int. J. Urology, 2006, 13, 308-310.

Petrakis i.E., Grysbolaki E., Paraskakis S., Lagoudis T., Filis D. \& Chalkiadakis G. Pseudotumoral hydatid cyst: report of a case. HPB Surgery, 2009, doi:10.1155/2009/137956

Prousalidis J., Tzardinoglou E., Kosmidis C., Kaltsohis K. \& AlETRAS C. Surgical management of calcified hydatid cysts of the liver. HPB Surgery, 1999, 11 (4), 253-259.

Prousalidis J., Kosmidis C.H., Fahantidis E., Harlaftis N. \& Aletras O. Surgical treatment of multiple cystic echinococcosis. HPB, 2004, 6 (2), 110-114.

Safioleas M., Nikiteas N., Stamatakos M., Safioleas C., Manti C.H., Revenas C. \& Safioleas P. Echinococcal cyst of the subcutaneous tissue: A rare case report. Parasitology International, 2007, 57, 236-238.

Schweiger A., Ammann R.W., Candinas D., Clavien P.A., Eckert J., Gottstein B., Halkic N., Muellhaupt B., Prinz B.M., Reichen J., Tarr P.E., Torgerson P.R. \& Deplazes P. Human alveolar echinococcosis after fox population increase, Switzerland. Emerg. Infect. Dis., 2007, 13 (6), 878-882.

Sotiraki S., Himonas C. \& Korkoliakou P. Hydatidosis-echinococcosis in Greece. Acta Tropica, 2003, 85, 197-201.

Tepetes K., Christodoulidis G., Spyridakis M. \& Hatzitheofilou K. Large solitary retroperitoneal echinococcal cyst: A rare case report. World J. Gastroenterol., 2007, 13 (45), 6101-6103.

Theodoropoulos G., Kolitsopoulos A., Archimandritis A. \& Melissinos K. Echinococcose alvéolaire hépatique. Trois observations en Grèce. Nouvelle Presse Médicale, 1978, 7 (34), 3056.

Thompson R.C. The taxonomy, phylogeny and transmission of Echinococcus. Exp. Parasitol., 2008, 119 (4), 439-446.

TSAGlas E. The epidemiological situation of the most important zoonoses in man and animals in Greece. Bull. Hell. Vet. Soc., 1985, 36 (1), 45-54.

TZAmouranis N. A review of the genus Echinococcus Rudolphi, 1801 and the related problems in Greece. Iatriki, 1969, 15, 475-498.

Vagianos C.E., Karavias D.D., KaKkos S.K., Vagenas C.A. \& ANDROULAKIS J.A. Conservative surgery in the treatment of hepatic hydatidosis. Eur.J. Surg., 1995, 161 (6), 415-420.

Varcasia A., Canu S., Kogkos A., Pipia A.P., Scala A., Garippa G. \& SEIMENIS A. Molecular characterization of Echinococcus granulosus in sheep and goats of Peloponnesus, Greece. Parasitol. Res., 2007, 101 (4), 1135-1139.

VAssalos M. Epizootiology of hydatidosis-echinococcosis in Greece. Bull. Hell. Vet. Med. Soc, 1978, 29, 53-57.

Vassalos M., Himonas C. \& Saravanos A. Hydatidosis in Greece, in: Some important infections in bovines, considered from the economic and social (zoonosis) points of view. Euzéby J \& Gevrey J. (Eds), Parasitological symposium, Lyon, 1983. CEC Brussels \& Luxemburg, 1984.

Voros D., Kalovidouris A., Gouliamos A., Vlachos L., Danias N. \& Papadimitriou J. The real incidence of extracapsular (satelite) cysts of liver Echinococcus. HPB Surgery, 1999, 11, 249-252.
Xiao N., Qiu J., Nakao M., Li T., Yang W. \& Chen X. Echinococcus shiquicus, a new species from the Qinghai-Tibet plateau region of China: discovery and epidemiological implications. Parasitol. Int., 2006, 55, S233-236.

Reçu le 6 mai 2010 Accepté le 17 juin 2010 